Military Technical College

Kobry El-Kobbah,

Cairo, Egypt

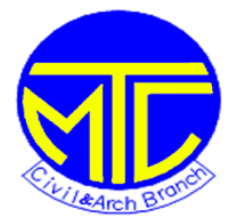

$11^{\text {th }}$ International Conference on Civil and Architecture Engineering

ICCAE-11-2016

\title{
Development of Application for Automatic Aerial Photogrammetric Project Planning
}

\author{
Dr. A. Serwa \\ BSc. MSc., PhD., MCP, MCSD, MCT \\ Faculty of Engineering in El-Mataria \\ Helwan University, Cairo, Egypt. \\ Dr.A.Serwa@m-eng.helwan.edu.eg
}

\begin{abstract}
Aerial Photogrammetry is one of engineering surveying operations which is a traditional methodology that can be used to map the earth.The rapid development in instrumentation and computer dependency led to the need to develop open-source photogrammetric software (SW). Aerial imagery (analogue and digital) process is a corner of the pillars of Aerial Photogrammetry.This research is a trial to simulate aerial imagery on a dynamic virtual map. The developed SW is called Application for Automatic Aerial Photogrammetric Project Planning (3A3P). 3A3P enablesplanning engineers and photogrammiststoimagine aerial imaging process.Besides, 3A3P makes all the calculations that are required for planning process. 3A3P producesvirtual aerial maps automatically based on the proposedarea information, imaging camera characteristics and specifications of the imagery as well as to the purpose of the imageryor the desired product. Then perform calculations that are required for the planning process also full information map can be produced.A detailed report of the imagery process can be produced including exposure stations coordinates and the proposed flight mission map.
\end{abstract}

KEY WORDS:Aerial Photogrammetry;Simulation;Imagery; Virtual Map;Open Source; SW Development. 